[Chem. Pharm. Bull.

[34(10)4265-4272(1986)]

\title{
Intestinal Absorption Characteristics of 5-Fluorouracil, Ftorafur and 6-Mercaptopurine in Rats
}

\author{
Hitoshi Sasaki, Junzo Nakamura, Ryoji Konishi \\ and JUICHIRO SHIBASAKI* \\ Faculty of Pharmaceutical Sciences, Nagasaki University, \\ Bunkyo-machi 1-14, Nagasaki 852, Japan
}

(Received March 8, 1986)

\begin{abstract}
The absorption characteristics of three anticancer antimetabolites, 5-fluorouracil (5-FU), ftorafur and 6-mercaptopurine (6-MP), were investigated by in vitro and in situ absorption techniques in rats. Absorption of a nucleic acid, uracil, was also investigated. In the in situ experiment, the disappearance ratios of uracil, 5-FU and 6-MP from the lumen showed a dependency on initial drug concentration, although ftorafur was absorbed at a constant rate regardless of the initial concentration. At low concentrations, Michaelis-Menten type processes were involved in the disappearance of uracil, 5-FU and 6-MP as judged from reciprocal plots. No metabolite of uracil, 5-FU or ftorafur was detected in the experiments. Most of the 6-MP that was lost from the lumen appeared as its metabolite, 6-thiouric acid, in the lumen. The in vitro data supported the results of the in situ experiment. In particular, uracil and 5-FU showed the ability to permeate at low concentrations against a concentration gradient. A small serosal transfer of 6-MP and the selective appearance of 6-thiouric acid on the mucosal side were confirmed. Metabolic inhibitors, 2,4-dinitrophenol and ouabain, strongly depressed the disappearance and transfer of uracil and 5-FU, but not ftorafur. The absorption and metabolism of 6-MP were affected by 2,4dinitrophenol, but not ouabain.
\end{abstract}

Keywords-antimetabolite; 5-fluorouracil; ftorafur; 6-mercaptopurine; intestinal absorption; in vitro technique; in situ technique; intestinal metabolism; 2,4-dinitrophenol; ouabain

Antimetabolites have been widely used in cancer chemotherapy because these drugs inhibit the growth of cancer cells selectively; analogs of nucleic acids are examples. ${ }^{1)}$ The similarity of these compounds to biological components often results in complex behavior as regards absorption, metabolism and uptake by cells. ${ }^{2)}$ 5-Fluorouracil (5-FU) and 6-mercaptopurine (6-MP) are typical pyrimidine and purine analogs, respectively, and are mainly used as oral dosage forms. ${ }^{3)}$ Ftorafur was developed as a lipophilic masked derivative of 5-FU to improve the absorbability and retention of effect after oral administration. ${ }^{4)}$ Assessment of the absorption characteristics is important for the design of an effective administration regimen and the development of suitable dosage forms because absorption is the first step in the drug action.

Therefore, in the present study, the absorption characteristics of uracil, 5-FU, ftorafur and 6-MP were investigated by means of in vitro and in situ absorption techniques in rats.

\section{Experimental}

Materials__ Uracil and 5-FU were supplied by Kyowa Hakko Kogyo Co. Ftorafur and 6-MP were supplied by Taiho Yakuhin Co. and Sankyo Company, Ltd., respectively. Authentic 6-thiouric acid, which is a metabolite of 6MP, was prepared and purified as described by Elion et al. ${ }^{5)}$ All other chemicals were of reagent grade.

Detection of Metabolite by Thin Layer Chromatography (TLC)__- In situ and in vitro perfusate at the end of an experiment was lyophilized and the residue was dissolved in a little acetone. An aliquot of the acetone solution was applied to a TLC plate (Kieselgel $60 \mathrm{HF}_{254}$, Merck) and developed with the following developers: for pyrimidines, (1) 
ethyl acetate : acetone $:$ water $=30: 25: 5$, (2) ethyl acetate $:$ formic acid $:$ water $=65: 5: 5$, (3) $n$-butanol : acetic acid : water $=50: 5: 15$; for purine, (4) acetonitrile : dil. $\mathrm{NH}_{4} \mathrm{OH}=7: 3,(5) n$-butanol : benzene : water $=2: 1: 1$.

In Situ Absorption Experiment__ In situ absorption was carried out according to Kakemi et al. ${ }^{6)}$ Male Wistar albino rats $(150-200 \mathrm{~g})$ were fasted overnight and allowed free access to water. Animals were anesthetized with pentobarbital, given intraperitoneally. A midline incision was made, then the intestine was cannulated at the duodenal and ileal ends, and the bile duct was ligated. The intestine was replaced in the abdomen and the incision was closed. The luminal side of the intestine was washed with warm saline and drug solution prior to recirculation. Drug solution $(50 \mathrm{ml})$, maintained at $37^{\circ} \mathrm{C}$, was passed through the intestine, from the pylorus to the ileocecal junction, by using an infusion pump at a rate of $10 \mathrm{ml} / \mathrm{min}$ for $90 \mathrm{~min}$. The perfusate was an isotonic $\mathrm{pH} 7.2 \mathrm{buffer}(\mathrm{NaCl} 145 \mathrm{~mm}$, $\mathrm{KCl} 4.56 \mathrm{mM}, \mathrm{CaCl}_{2} 1.25 \mathrm{mM}, \mathrm{Na}_{2} \mathrm{HPO}_{4} 1.33 \mathrm{~mm}, \mathrm{NaH}_{2} \mathrm{PO}_{4} 0.33 \mathrm{~mm}$ ) containing various amounts of drug and phenol red as an indicator of water movement, as reported by Schanker and Tocco. ${ }^{7)}$ Rectal temperature was maintained at $37 \pm 1^{\circ} \mathrm{C}$. After recirculation for $90 \mathrm{~min}$, the sample solution was withdrawn. The concentrations of the drug and phenol red in samples were determined spectrophotometrically. The disappearance of the drug was corrected based on the change of phenol red concentration.

In Vitro Absorption Experiment_ In vitro intestinal everted sacs were prepared as reported by Wilson and Wiseman. ${ }^{8)}$ Rats $(160-230 \mathrm{~g})$ were treated as in the in situ absorption experiments. Krebs-Ringer bicarbonate solution ( $\mathrm{pH} 7.4$ ) containing $0.1 \%$ glucose was used as the incubation medium. The small intestine was washed with buffer solution, maintained at $37^{\circ} \mathrm{C}$, and isolated. An intestinal segment (jejunum, $25 \mathrm{~cm}$ ) was everted with a wire so that the mucosal surface was on the outside, ligated at both ends, and filled with $3 \mathrm{ml}$ of $\mathrm{pH} 7.4$ buffer solution in the serosal lumen. Immediately after ligation, each everted sac was placed in a centrifuge tube containing $10 \mathrm{ml}$ of drug solution at various concentrations and incubated for $60 \mathrm{~min}$ at $37^{\circ} \mathrm{C}$. The drug solution was saturated with $95 \% \mathrm{O}_{2}$ and $5 \% \mathrm{CO}_{2}$. The amount of drug that disappeared from the incubation medium was calculated as the difference in concentration between the initial solution and final solution. At the end of the incubation period, the buffer volumes on the serosal and mucosal sides were determined.

In the experiment on inhibitor effect, 2,4-dinitrophenol (DNP) or ouabain was contained in both the mucosal and serosal solutions at a concentration of 0.2 or $2.0 \mathrm{mM}$, respectively.

Analytical Methods_-Uracil and 5-FU were assayed by the spectrophotometric method reported by Schanker and Tocco. ${ }^{7)}$ Samples were diluted with $0.1 \mathrm{M} \mathrm{HCl}$ and washed with ethyl acetate, then the drug concentration in the aqueous layer was determined from the absorbance difference at $260 \mathrm{~nm}$ and $280 \mathrm{~nm}$. Ftorafur was also assayed spectrophotometrically. The sample was extracted with chloroform in $\mathrm{pH} 5.2$ acetate buffer $(0.1 \mathrm{M})$ and the organic layer was re-extracted with $\mathrm{pH} 11.0$ carbonate buffer $(0.1 \mathrm{M})$. The drug concentration in the aqueous phase was determined spectrophotometrically at $270 \mathrm{~nm}$.

Separate assays of 6-MP and 6-thiouric acid were carried out by spectrophotometric determination at $327 \mathrm{~nm}$ and $355 \mathrm{~nm}$ in the aqueous phase after washing with ethyl acetate. The concentrations were calculated by means of the following two equations.

$$
\begin{aligned}
& \text { absorbance at } 327 \mathrm{~nm}=E_{1} \times C_{1}+E_{2} \times C_{2} \\
& \text { absorbance at } 355 \mathrm{~nm}=E_{3} \times C_{1}+E_{4} \times C_{2}
\end{aligned}
$$

$C_{1}$ and $C_{2}$ are the concentrations of 6-MP and 6-thiouric acid, respectively, and $E_{1}-E_{4}$ are molar absorption coefficients determined from calibration curves of 6-MP and 6-thiouric acid at $327 \mathrm{~nm}$ and $355 \mathrm{~nm}$, respectively.

In the experiment on inhibitor effect, DNP was removed from samples by extraction with toluene since it interfered with the determination. Ouabain did not affect these assays.

Phenol red, used as an indicator of water movement in the in situ experiment, was assayed at $550 \mathrm{~nm}$ after sufficient dilution of the sample with $1.0 \mathrm{M} \mathrm{NaOH}$. This dye did not interfere with the above assays.

Calculation of Apparent Kinetic Parameters-Calculation of apparent parameters in situ was carried out with a microcomputer by the simplex method using the nonlinear least-squares program reported by Yamaoka and Nakagawa. ${ }^{9)}$

\section{Results}

\section{Detection of Metabolite}

6-Thiouric acid was formed as a metabolite of 6-MP in the in situ and in vitro experiments, although no metabolite of uracil, 5-FU or ftorafur was detected by TLC analysis.

\section{In Situ Absorption Experiment}

The effects of initial drug concentration on the disappearance of compounds and the appearance of the metabolite in the lumen in situ are shown in Fig. 1 (A: uracil, 5-FU and 

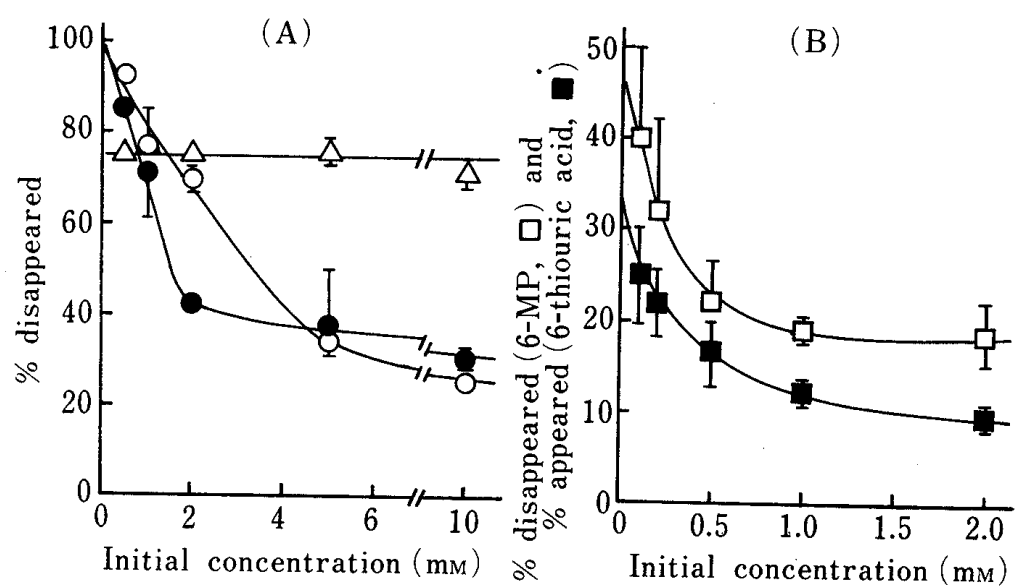

Fig. 1. Effect of Initial Concentration on the Disappearance of Uracil, 5-FU, Ftorafur and 6-MP from the Lumen, and Appearance of 6-Thiouric Acid in the Lumen in Situ

(A) $\bigcirc$, uracil; $\bullet$, 5-FU; $\triangle$, ftorafur. (B) $\square$, 6-MP disappearance; $\mathbf{\square}$, 6-thiouric acid appearance. Each point represents the mean \pm S.E. of at least four experiments.
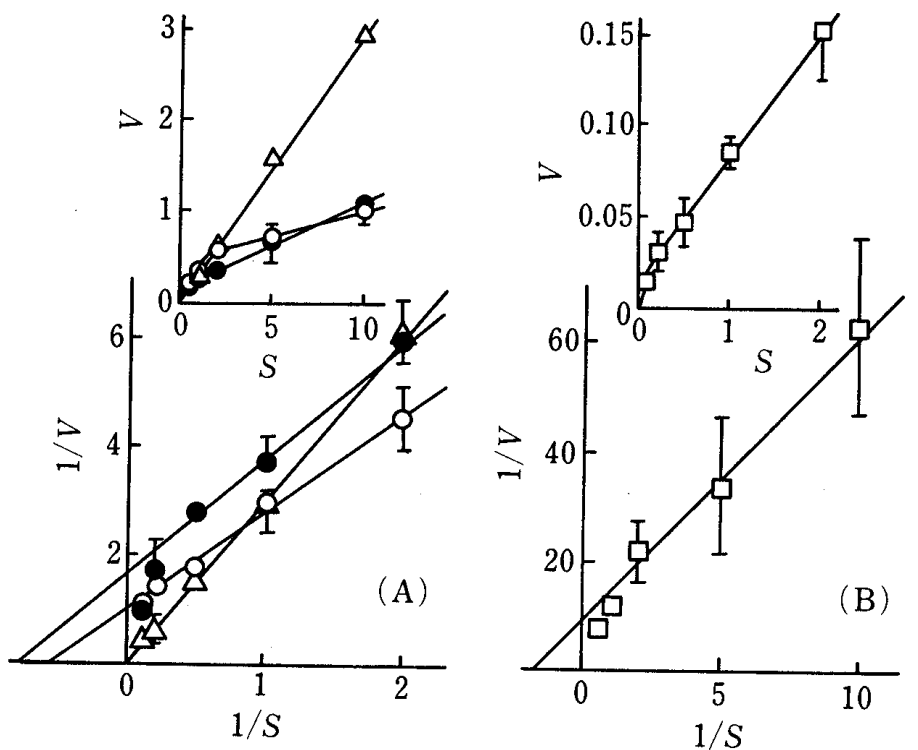

Fig. 2. Lineweaver-Burk Plot of the Disappearance Data in Situ

(A) $\mathrm{O}$, uracil; - 5-FU; $\triangle$, ftorafur. (B) $\square, 6-$ MP. $S$ : Initial concentration (mM). $V$ : Disappearance velocity $(\mathrm{mm} / \mathrm{h} / 100 \mathrm{~g})$. Each point represents the mean \pm S.E. of at least four experiments.

ftorafur. B: 6-MP and 6-thiouric acid). The absorption ratios of uracil and 5-FU were dependent on the initial drug concentration. At low concentration, uracil and 5-FU were mostly absorbed, and increase of the drug concentration decreased the disappearance. However, ftorafur was absorbed to a constant extent, regardless of concentration. The disappearance ratio of 6-MP was also dependent on initial drug concentration and most the 6MP lost appeared in the lumen as 6-thiouric acid.

From these results, the velocities of disappearance in $1 \mathrm{~h}$ per $100 \mathrm{~g}$ body weight were calculated. The reciprocals of the velocity and initial drug concentrations in the perfusate were plotted (Lineweaver-Burk plot) as shown in Fig. 2 (A: uracil, 5-FU and ftorafur. B: 6-MP). Ftorafur gave a straight line passing through the origin, while the plots for uracil, 5-FU and 6MP were linear with intercepts at low concentrations. The plots of the velocities versus initial drug concentrations are included in Fig. 2. 


\section{Kinetic Analysis}

The in situ absorption data were analyzed kinetically. The apparent parameters of disappearance of each compound from the lumen were calculated by using the following equations:

$$
\begin{aligned}
& V=K \times S \\
& V=K \times S+\left(V_{\max } \times S\right) /\left(K_{\mathrm{m}}+S\right)
\end{aligned}
$$

Equation 1 was used for ftorafur and Eq. 2 was used for uracil, 5-FU and 6-MP; $V, S$ and $K$ are the disappearance velocity in $1 \mathrm{~h}$ per $100 \mathrm{~g}$ body weight, the initial drug amount in the perfusate, and the passive diffusion constant, respectively. $K_{\mathrm{m}}$ and $V_{\max }$ are the Michaelis constant and maximum disappearance velocity in the particular absorption process. The computer-assessed kinetic parameters of uracil, 5-FU, ftorafur and 6-MP are summarized in Table I. The values of $K_{\mathrm{m}}$ and $V_{\max }$ of 5-FU were lower than those of uracil. 6-MP had remarkably small values of $K_{\mathrm{m}}$ and $V_{\max }$. The lipophilic masked compound, ftorafur, showed a higher passive absorption constant than the parent drug, 5-FU.

\section{In Vitro Absorption Experiment}

The in vitro results are expressed as drug disappearance from the mucosal side and the ratio of drug concentration on the serosal side against that on the mucosal side ( $S / M$. ratio). During the in vitro absorption experiment, no marked change of the serosal and mucosal volumes was observed.

The effects of mucosal initial concentration on the disappearance and $S / M$ ratio of uracil

Table I. Computer-Assessed Kinetic Parameters of the Absorption Processes of Antimetabolites

\begin{tabular}{lccc}
\hline \hline Substance & $\begin{array}{c}K_{\mathrm{m}} \\
(\mathrm{mM})\end{array}$ & $\begin{array}{c}V_{\max } \\
(\mathrm{mM} / \mathrm{h} / 100 \mathrm{~g})\end{array}$ & $\begin{array}{c}K \\
(1 / \mathrm{h} / 100 \mathrm{~g})\end{array}$ \\
\hline Uracil & 1.06 & 0.688 & 0.038 \\
5-FU & 0.26 & 0.204 & 0.093 \\
Ftorafur & - & - & 0.305 \\
6-MP & 0.047 & 0.015 & 0.069 \\
\hline
\end{tabular}
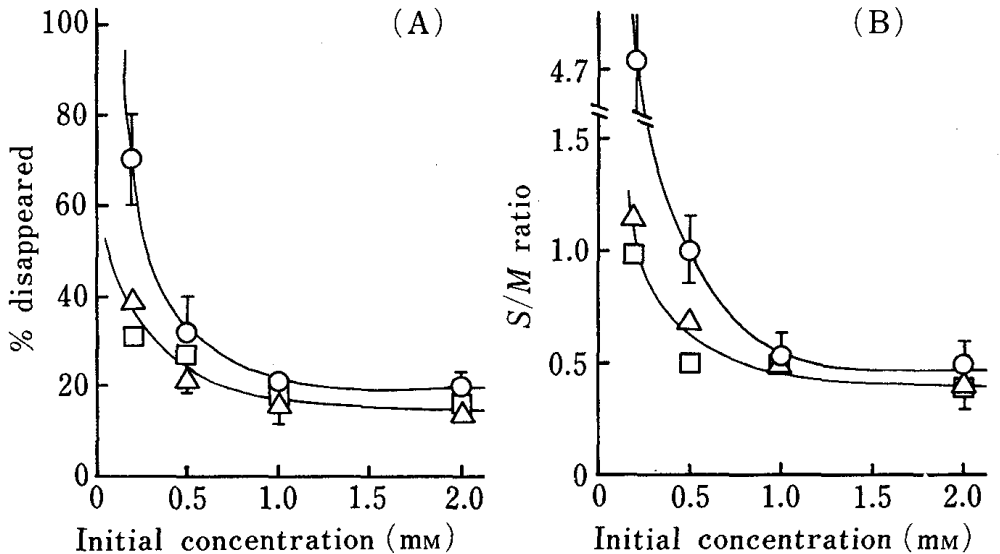

Fig. 3. Effect of Initial Concentration on the Disappearance from the Mucosal Side and the $S / M$ Ratio of Uracil with or without Inhibitor in Vitro

(A) Disappearance $O$, uracil alone; $\triangle$, with DNP; $\square$, with ouabain. (B) $S / M$ Ratio $O$, uracil alone; $\triangle$, with DNP; $\square$, with ouabain. Each point represents the mean \pm S.E. of at least three experiments except in some cases (two experiments; 0.2 and $0.5 \mathrm{~mm}$ with DNP and with ouabain). 

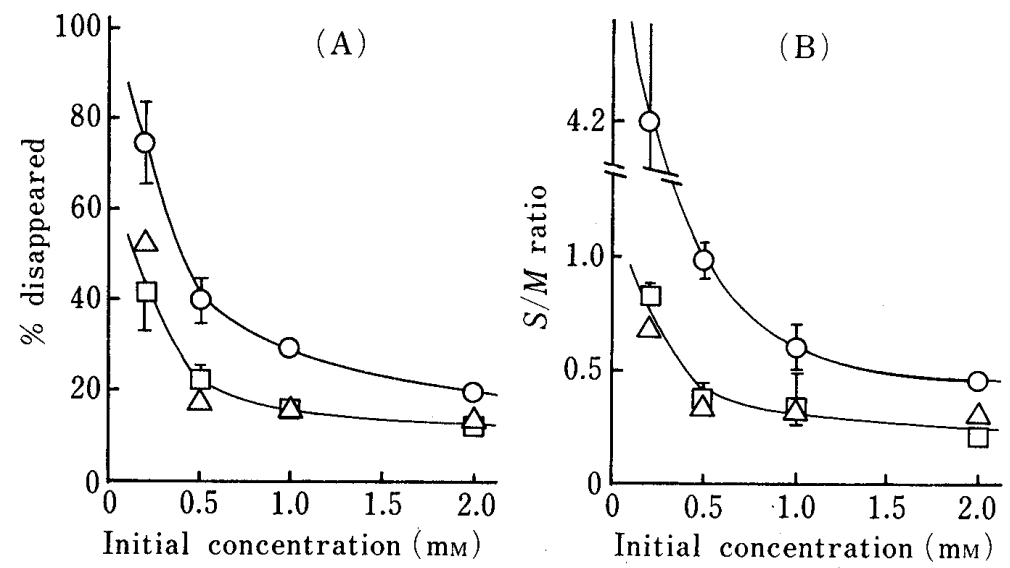

Fig. 4. Effect of Initial Concentration on the Disappearance from the Mucosal Side and the $S / M$ Ratio of 5-FU with or without Inhibitor in Vitro

(A) Disappearance $O$, 5-FU alone; $\triangle$, with DNP; $\square$, with ouabain. (B) $S / M$ Ratio $\bigcirc, 5$ FU alone; $\triangle$, with DNP; $\square$, with ouabain. Each point represents the mean \pm S.E. of at least three experiments except in some cases (two experiments; $0.2,0.5$ and $1.0 \mathrm{mM}$ with DNP and with ouabain).
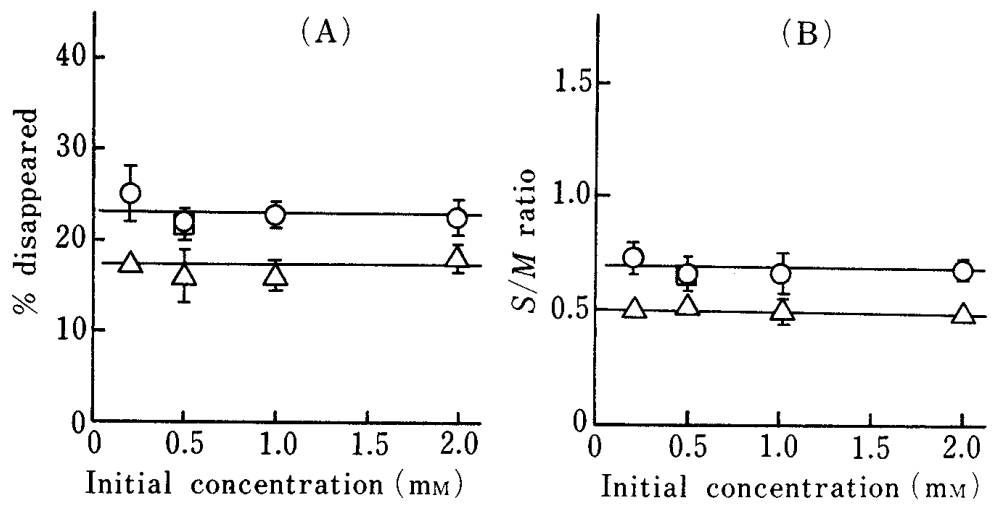

Fig. 5. Effect of Initial Concentration on the Disappearance from the Mucosal Side and the $S / M$ Ratio of Ftorafur with or without Inhibitor in Vitro

(A) Disappearance $\bigcirc$, ftorafur alone; $\triangle$, with DNP; $\square$, with ouabain. (B) $S / M$ Ratio $\bigcirc$, ftorafur alone; $\triangle$, with DNP; $\square$, with ouabain. Each point represents the mean \pm S.E. of at least three experiments except in some cases (two experiments; 0.2 and $0.5 \mathrm{~mm}$ with DNP and with ouabain).

with or without inhibitors are shown in Fig. 3 (A, B). Disappearance of uracil from the mucosal side was dependent on its initial concentration, and its $S / M$ ratio was over 1 at $0.2 \mathrm{~mm}$. Coadministration of DNP or ouabain with uracil depressed the disappearance and the ratio.

Figure $4(\mathrm{~A}, \mathrm{~B})$ shows the in vitro absorption behavior of 5-FU. 5-FU also showed dependence of the disappearance on mucosal drug concentration and gave a high $S / M$ ratio at lower concentrations. The metabolic inhibitors depressed the permeation of the drug.

In contrast, ftorafur disappeared at a constant rate regardless of the initial concentration. The $S / M$ ratio was constant below 1 as shown in Fig. 5 (A, B). Ouabain did not inhibit the absorption of $0.5 \mathrm{~mm}$ ftorafur, although DNP showed a slight but constant inhibition regardless of the initial concentration.

The disappearance and $S / M$ ratio of a purine compound, 6-MP, are presented in Fig. 6 (A, B). 6-MP disappearance depended on the initial concentration, and the $S / M$ ratio was small. Ouabain affected the behavior of 6-MP slightly. DNP increased the $S / M$ ratio, although it decreased the disappearance from the mucosal side. 

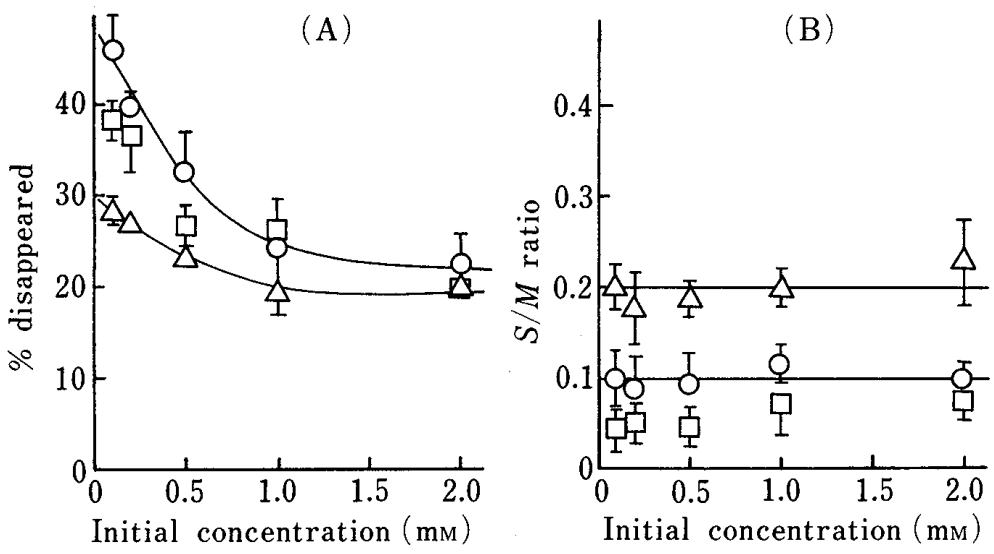

Fig. 6. Effect of Initial Concentration on the Disappearance from the Mucosal Side and the $S / M$ Ratio of 6-MP with or without Inhibitor in Vitro

(A) Disappearance $\bigcirc, 6$-MP alone; $\triangle$, with DNP; $\square$, with ouabain. (B) $S / M$ Ratio $O$, 6MP alone; $\triangle$, with DNP; $\square$, with ouabain. Each point represents the mean \pm S.E. of at least three experiments.
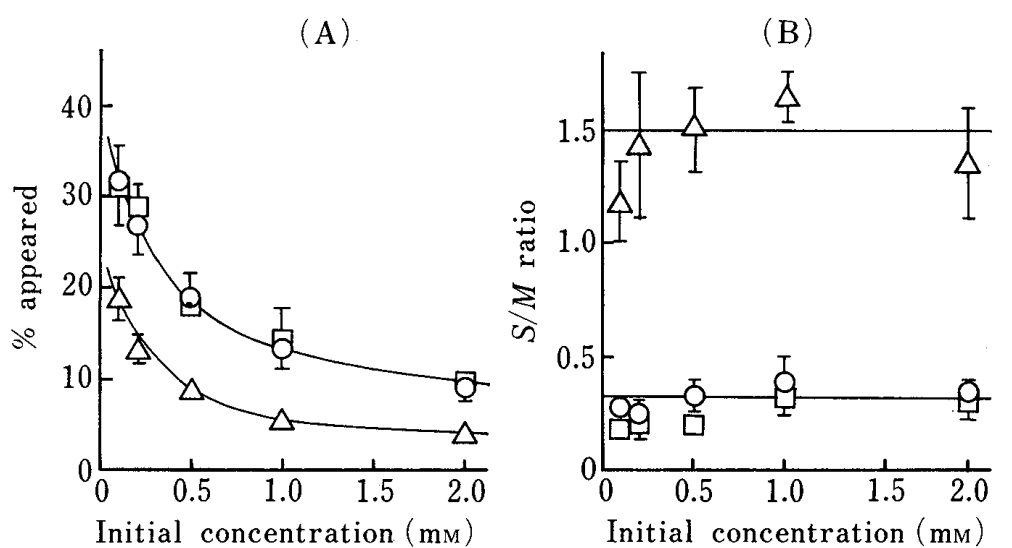

Fig. 7. Effect of Initial Concentration of 6-MP on Appearance on the Mucosal Side and the $S / M$ Ratio of 6-Thiouric Acid with or without Inhibitor in Vitro

(A) Appearance $O$, 6-MP alone; $\triangle$, with DNP; $\square$, with ouabain. (B) $S / M$ Ratio $\bigcirc$, 6MP alone; $\triangle$, with DNP; $\square$, with ouabain. Each point represents the mean \pm S.E. of at least three experiments.

The behavior of 6-thiouric acid in the same experiment is shown in Fig. 7 (A, B). 6Thiouric acid appearance on the mucosal side was also dependent on the initial concentration of 6-MP. Most of the lost 6-MP appeared on the mucosal side as its metabolite, 6-thiouric acid, especially at low initial concentrations. The $S / M$ ratio was small. Ouabain had no influence on the behavior of 6-thiouric acid. DNP suppressed the production of 6-thiouric acid.

\section{Discussion}

Generally, the absorption behavior of most drugs is consistent with the $\mathrm{pH}$-partition theory. Furthermore it is well known that some substances are absorbed by specific mechanisms. The existence of active transport was reported for purine, pyrimidine and their analogs. ${ }^{10)}$ However, few comparative studies on the absorption characteristics using both in vitro and in situ techniques have been done. In this work, we investigated the absorption processes of uracil, 5-FU, ftorafur and 6-MP.

The synthetic pyrimidine analog, 5-FU, has been used clinically for the treatment of 
carcinoma of the breast and gastrointestinal tract. ${ }^{11)}$ Schanker et al. ${ }^{10)}$ and Muranishi et al. ${ }^{12)}$ demonstrated that 5-FU crossed the small-intestinal epithelium by active transport as well as passive diffusion. In the present study, the absorptions of uracil and 5-FU showed a dependency on drug concentration (Fig. 1A). The reciprocal plot was linear at lower concentrations with a positive intercept, suggesting that the absorption occurs by a Michaelis-Menten type process (Fig. 2A). The values of $K_{\mathrm{m}}$ and $V_{\max }$ of 5-FU absorption were slightly smaller than those of uracil absorption (Table I).

The dependency of the absorption ratio of uracil or 5-FU on initial drug concentration was supported by the in vitro experiment (Fig. 3A and Fig. 4A). Especially at low concentrations, uracil and 5-FU were transferred from the mucosa to the serosa against a concentration gradient, suggesting that active transport occurs (Fig. 3B and Fig. 4B). Active transport is usually affected by various chemical substances. ${ }^{13)}$ Therefore, the effects of DNP and ouabain were investigated (Fig. 3A, B and Fig. 4A, B). DNP is an uncoupler of the respiratory chain and oxidative phosphorylation, and ouabain is an inhibitor of ATPase. Both inhibitors reduced the disappearance from the mucosal side as well as the $S / M$ ratio for uracil and 5-FU, especially at low initial concentrations. The $S / M$ ratio at $0.2 \mathrm{~mm}$ was not higher than about 1 . Therefore, active transport is the predominant mode of absorption at low concentrations of these compounds, whereas passive diffusion predominates at high concentrations, at which the active process is saturated. These in vitro and in situ results are consistent with the previous results. ${ }^{10,12)}$

Ftorafur was developed as a lipophilic masked derivative of 5-FU for oral use, and shows significant activity against several adenocarcinomas with lower myelotoxicity than 5-FU. ${ }^{14)}$ Few data are available on the absorption of ftorafur, although the mechanism was considered to be passive diffusion because of the good drug absorbability in vivo. ${ }^{15)}$ In this absorption study, ftorafur was absorbed at a constant rate irrespective of the initial concentration, in situ and in vitro (Fig. 1A and Fig. 5A). The in situ reciprocal plot was linear, passing through the origin (Fig. 2A). The in vitro $S / M$ ratio was also constant, below 1 (Fig. 5B). Ouabain did not inhibit the absorption of $0.2 \mathrm{~mm}$ ftorafur. DNP showed slight inhibition, but with no concentration dependency. These in vitro and in situ results support the view that ftorafur was absorbed by passive diffusion. The passive diffusion constant, determined from the in situ results, was higher than that of 5-FU (Table I), suggesting that the lipophilic prodrug approach is useful for improving drug absorbability. We have also reported several examples of a lipophilic prodrug approach. ${ }^{16)}$

Using the same techniques, 6-MP, a purine-type antimetabolite was evaluated. 6-MP is used clinically against various leukemias and is administered orally, though little work has been done on its absorption. ${ }^{17)}$ In the present study, the disappearance of 6-MP was not large, and was dependent on the initial concentration (Fig. 1B). The reciprocal plot indicated that the disappearance at the lower concentrations followed Michaelis-Menten type kinetics (Fig. 2B). However, the absorption constants of 6-MP, $K_{\mathrm{m}}, V_{\max }$ and $K$, were small in comparison with those of pyrimidines (Table I). The dependence of 6-MP disappearance on initial concentration and the small $S / M$ ratio were supported by the in vitro results.

6-MP is normally metabolized to thiouric acid by xanthine oxidase in vivo. ${ }^{18)}$ In fact, a large part of the lost 6-MP appeared in the lumen as 6-thiouric acid both in vitro and in situ (Fig. 1A and Fig. 7). These results indicate that the intestinal first-pass metabolism of 6MP will be large after oral administration. Sackler ${ }^{19)}$ demonstrated that the oxidative activity toward hypoxanthine per gram wet weight of tissue was 100 fold greater in the intestine than in hepatic tissue. Ding and Benet ${ }^{20)}$ reported the systemic availability of 6-MP after oral administration to be $12 \%$ in rhesus monkey.

The appearance of 6-thiouric acid on the mucosal side was greater than that on the serosal side (Fig. 7B). No conversion of 6-MP to 6-thiouric acid in the perfusate was observed, 
and authentic 6-thiouric acid was hardly absorbed in vitro or in situ (data not shown). Thus, the oxidative enzyme may directly convert luminal 6-MP to 6-thiouric acid. Sackler ${ }^{19)}$ reported that xanthine oxidase is localized at the brush border area of the mucosal epithelial cells. Consequently, DNP could decrease both the production of 6-thiouric acid and the disappearance of 6-MP in the lumen by inhibition of the enzyme in the brush border area (Figs. 6 and 7). However, there is another possibility. Berlin and Hawkins ${ }^{21)}$ demonstrated that a purine secretion system exists in rodent intestine, and this process was greatly reduced by DNP. The metabolite of 6-MP, 6-thiouric acid, might be a substrate for the intestinal secretion mechanism. Yasuhara $e t a l .^{22)}$ reported that a metabolite of $p$-aminobenzoic acid in the intestinal tissue is released selectively on the luminal side. Although further work is necessary, the present results should contribute to the design of oral dosage forms of anticancer antimetabolites.

\section{References}

1) C. Heidelberger, Annu. Rev. Pharmacol., 7, 101 (1967); G. B. Grindey, Cancer Treat. Rev., 6, 19 (1979).

2) C. Benz and E. Cadman, Cancer Res., 41, 994 (1981); R. I. Walker, W. L. Horvath, W. S. Rule, J. C. Herion and J. G. Palmer, Cancer Res., 33, 755 (1973); S. Fujii, K. Ikenaka, M. Fukushima and T. Shirasaka, Gann, 69, 763 (1978).

3) G. B. Elion, E. Burgi and G. H. Hitchings, J. Am. Chem. Soc., 74, 411 (1952); R. Duschinsky, E. Pleven and C. Heidelberger, J. Am. Chem. Soc., 79, 4559 (1957).

4) S. Hillers, R. A. Zhuk and M. Lidaks, Dokl. Akad. Nauk SSSR, 176, 332 (1967).

5) G. B. Elion, S. Mueller and G. H. Hitchings, J. Am. Chem. Soc., 81, 3042 (1959).

6) T. Koizumi, T. Arita and K. Kakemi, Chem. Pharm. Bull., 12, 421 (1964).

7) L. S. Schanker and D. J. Tocco, J. Pharmacol. Exp. Ther., 128, 115 (1960).

8) T. H. Wilson and G. Wiseman, J. Physiol. (London), 123, 116 (1954).

9) K. Yamaoka and T. Nakagawa, J. Pharmacobio-Dyn., 6, 595 (1983).

10) L. S. Schanker and D. J. Tocco, Biochim. Biophys. Acta, 56, 469 (1962); L. S. Schanker and J. J. Jeffrey, Biochem. Pharmacol., 11, 961 (1962); R. D. Berlin, Science, 168, 1539 (1970).

11) C. Heidelberger and F. J. Ansfield, Cancer Res., 23, 1226 (1963).

12) S. Muranishi, H. Yoshikawa and H. Sezaki, J. Pharmacobio-Dyn., 2, 286 (1979).

13) A. Begleiter, H-Y. P. Lam, J. Grover, E. Froese and G. J. Goldenberg, Cancer Res., 39, 353 (1979); C. F. George and B. S. Gruchy, J. Pharm. Pharmacol., 31, 643 (1979).

14) J. A. Benvenuto, K. Lu, S. W. Hall, R. S. Benjamin and T. L. Loo, Cancer Res., 38, 3867 (1978).

15) S. Fujii, H. Okuda, H. Toide, N. Watanabe, K. Taira and S. Hashimoto, Oyo Yakuri, 8, 589 (1974).

16) H. Sasaki, T. Kakutani, M. Hashida and H. Sezaki, J. Pharm. Pharmacol., 37, 461 (1985); H. Sasaki, T. Takahashi, J. Nakamura, R. Konishi and J. Shibasaki, J. Pharm. Sci., 75, 676 (1986).

17) W. R. Ravis, J. S. Wang and S. Feldman, Biochem. Pharmacol., 33, 443 (1984).

18) G. B. Elion, S. Bieber and G. H. Hitchings, Ann. N. Y. Acad. Sci., 60, 297 (1954); E. J. Sarcione and L. Stutzman, Cancer Res., 20, 387 (1960).

19) M. L. Sackler, J. Histochem. Cytochem., 11, 326 (1969).

20) T. L. Ding and L. Z. Benet, Drug Metab. Dispos., 7, 373 (1979).

21) R. P. Berlin and R. A. Hawkins, Am. J. Physiol., 215, 932 (1968); R. P. Berlin and R. A. Hawkins, Am. J. Physiol., 215, 942 (1968).

22) M. Yasuhara, H. Kobayashi, Y. Kurosaki, T. Kimura, S. Muranishi and H. Sezaki, J. Pharmacobio-Dyn., 2, 177 (1979). 